Acting upon this and other considerations, to which we need not further allude, the Commission unanimously came to the conclusion that the remedy they were seeking lay, not in the formation of a separate Department for Ireland-which, indeed, they went on to say would be detrimental to the interests of Science and Art in that country-but in the consolidation and better administration of the existing institutions, and in the filling up of some obvious gaps, The essence of their recommendations was the amalgamation of several of the collections into an institution strongly resembling the South Kensington Museum, but covering a wider field, which should be administered by a director, who should be in immediate relation not only with the Minister of Education, but also with the Irish Government. This scheme, however, had a great drawback in the eyes of many of the leading noblemen and gentlemen in Ireland who were interested in the existing institutions, because it entailed the deprivation in the case of the two principal societies - the Royal Dublin Society and the Royal Irish Academy - of the privileges they had hitherto enjoyed of administering large public funds voted for the Natural History Museum and the Botanic Gardens, as well as other institutions. This objection and, possibly, the economical views of the late Government, have sufficed to keep this question in abeyance since 1868 ; but it now appears that the present Government have determined to take some decided step, for they have, we understand, during the last few days communicated with the bodies principally intercsted in the scheme.

From the information which has reached us we gather that the plan now proposed is as complete as that indi-

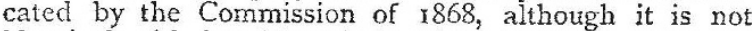
identical with it. Thus it has been decided to build a Science and Art Museum for Ireland similar to that now existing in Edinburgh. This will occupy a site adjacent to the principal buildings which now exist, and will consist of collections analogous to those of the South Kensington Museum, to which will be added the antiquarian collection of the Royal Irish Academy, and the industrial collection of the old Museum of Irish Industry. The building will also provide space for the Natural History Museurn and Geological Collection, and will thus set free the present Natural History Museum, to which the library of the Royal Dublin Society will be transferred and formed into a public National Library.

As may be imagined, this comprehensive scheme will entail the expenditure of a large amount of public money, and the Government make the offer contingent on the surrender of the privileges to which we have before referred, and the vesting of all the property in the Government. With the view, however, of still enabling those who at present take so great an interest in the existing institutions to continue this useful co-operation and represent the special wants of the country, it is proposed that the new National Library shall be managed by a Council of twelve trustees-eight to be nominated by the Royal Dublin Society and four by the Government; while the administration of the Science and Art Museum, which is to be under a director appointed by the Crown, as in Scotland, will be controlled by a Board of twelve visitorsfour nominated by the Lord Lieutenant; five by the Royal Dublin Society; and three by the Royal Irish Academy.

It is not proposed to interfere with the functions of the societies we have named, and we are glad to see that the Government propose still to continue the aid they now give to them.

In making these proposals the Government has taken the opportunity of putting on record its appreciation of the eminent services which have been rendered to both art and science by the societies we have named, and makes it clear that the motive for suggesting any diminution of their independence is, that the wants of the com. munity with regard to such matters as public museums have now in Ireland, as long ago in England, outgrown the useful operation of private societies.

The surrender of what we may, we hope, without offence, term some of their ornamental functions, will no doubt be somewhat painful to their members; but we cannot suppose that they will allow their private feeling to stand in the way of a national scheme so rich in promise, and based on principles which we should be glad to see applied in other localities besides Dublin.

\section{MINIATURE PHYSICAL GEOGRAPHY}

THE sands of the Lower Bagshot series are exposed along the shore at Bournemouth and form the cliffs. They are agglutinated into a very friable sandstone, which

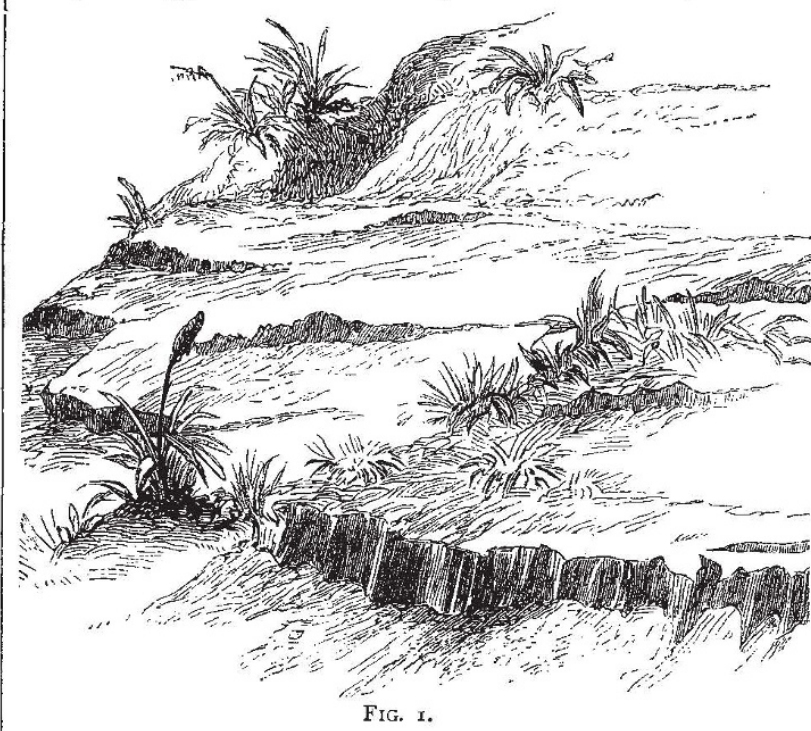

disintegrates under the influence of rain with extreme readiness. The siliceous grains are cemented together, probably by carbonate of lime. At any rate the adhesion of particle to particle is very slight and easily relaxed.
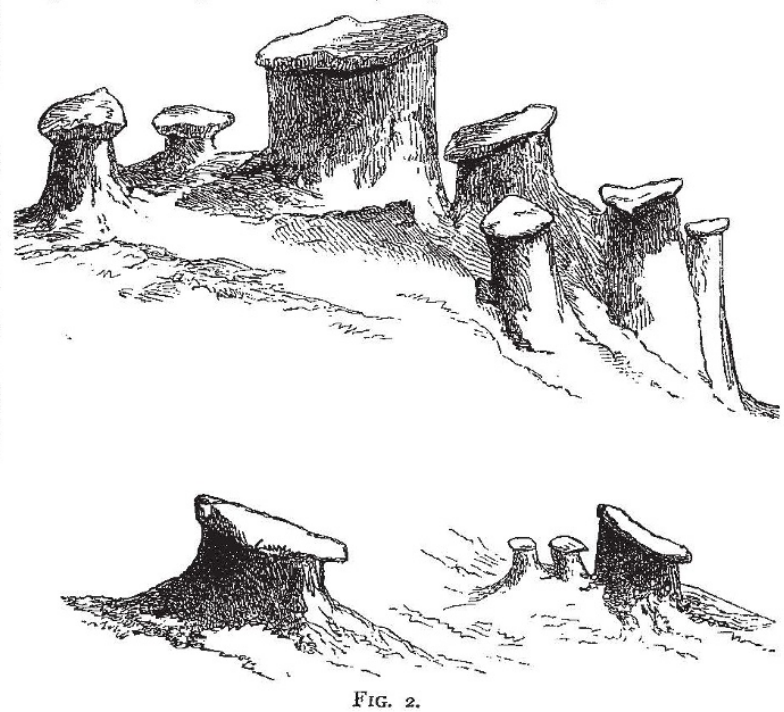

The result is that phenomena of erosion which elsewhere take years, centuries, ages, display themselves here on a miniature scale, and in a very short space of time. All the details of a river drainage system may be seen 
with perfect completeness in the space of a few square yards. Watersheds bounding contiguous basins, gently sloping plains, deeper valleys, steeply cut ravines may be recognised according as the rock varies here and there in more or less of cohesiveness.

The slight inequalities in this respect give rise to many other details worth noticing. On the vertical surface of the cliffs the rock is etched in a manner scarcely perceptible unless the sun shines obliquely on its surface. In this way a rock apparently homogeneous is seen to have been originally built up of layers deposited at the most various angles in the manner characteristic of what is called false bedding.

Here and there an undisturbed talus at the foot of a cliff has been permeated by water carrying some cementing material which feebly binds together again the incoherent sand. The base gets washed or blown away, and the surface of the talus is seamed with miniature landslips leaving steep and precipitous cliffs of the frightful height of at least two to three inches. These precipices are scored and columned with the sharpest fluting as they have been planed down by the subsiding soil (Fig. I reduced).

Here and there again the rock is traversed horizontally by layers, in which the cementing material is ferruginous. When the rock is denuded down to this it first gets washed pretty bare and then broken up into angular fragments by the frost. Each of these fragments protects the rock beneath, and so gradually gets mounted upon a little pedestal like the perched blocks of a Swiss glacier or the mud columns in the valley of Visp (Fig. 2, natural size).

T. D.

\section{PHYSICAL SCIENCE IN SCHOOLS}

THE struggle which Physical Science has had to 1 obtain a footing amongst the regular subjects of the school curriculum has not been altogether in vain, and the study of science now occupies a conspicuous place in the prospectus, at any rate, of many of our schools. But to those who, being behind the scenes, are acquainted with the real facts, the position which science occupies amongst other subjects, with a few honourable exceptions, is insignificant in the extreme. It is admitted as an axiom by all science teachers, that if the study of science is to be of any value, the student must, in some part at least of his work, be brought face to face with the facts of nature, and that unless this be the case the introduction of the subject into the school course is worse than useless; but how commonly does the so-called science-work of a school consist simply in the acquisition of so much "useful knowledge?" And even when in other respects the teaching is fairly satisfactory, the practical work is too often optional-an "extra," or taken on half-holidays, and so ruined by the competition of cricket and football.

We believe that a fair standard by which to judge of the present position of the study of science in schools is to be found in the "Regulations of the Oxford and Cambridge Schools Examination Board," and in the papers set at the examination for certificates (the first held) of July 1874 . Certificates are awarded to those who succeed in passing in a certain number of subjects; and the possession of such a certificate should indicate that a boy has obtained a thorough education up to the point fairly to be expected on leaving school.

Regulation 7 provides that "the examination for certificates shall include the following subjects :-

"Group I.-(1) Latin; (2) Greek ; (3) French and German.

"Group II.-(I) Mathematics (Elementary) ; (2) Mathematics (Additional).

"GroUp III.-(I) Scripture Knowledge ; (2) English ; (3) History.

"GROUP IV.-(I) Natural Philosophy ; (2) Heat and Chemistry ; (3) Botany; (4) Physical Geography and Elementary Geology.
Every candidate shall be required to satisfy the examiners in at least four subjects, taken from not less than three different groups."

From the foregoing Regulation, one would naturally suppose that equal value was attached to each of these subjects, an arrangement which would leave no room for the complaint that science did not receive its proper credit. Let us examine whether such is the case.

The examination papers show that out of more than fifty-two papers set, only four were set on scientific subjects. To pass in Latin it would seem that five different papers must be satisfactorily answered, in Greek four, in French and German eight, in Elementary Mathematics three, in Additional Mathematics four, in Scripture Knowledge three, in English three, in History one, in Natural Philosophy one, in Heat and Chemistry one, in Physical Geography one, in Botany one. We may not unfairly take these numbers as representing the relative value of the different subjects in the eyes of the compilers of the Regulations.

Thus, while a candidate who, having received his training in languages, selects, say Latin, French and German, English, and Elementary Mathematics, has to answer nineteen papers-the same certificate may be cheaply obtained from seven papers, by selecting Scripture Knowledge, Elementary Mathematics, Chemistry, and Physical Geography.

Next let us examine the kind of questions set. Elementary Mathematics means simply Arithmetic, Euclid, books i. and ii., and Algebra to simple equations. In Heat and Chemistry we find the following, amongst others (space does not permit to transcribe the whole paper).

I. Define "co-efficient of expansion." What relations subsist between the linear, superficial, and cubical expansion of a piece of iron?

2. Describe fully the successive changes which occur when a piece of ice is placed in an open vessel, and the vessel then gradually heated to, say, $150^{\circ} \mathrm{C}$.

3. What are our available sources of heat?

4. What degrees on the Centigrade scale correspond to $16^{\circ} \mathrm{R}$. and $-4^{\circ} \mathrm{F}$.? At what temperature will Fahrenheit and Centigrade thermometers give the same reading?

5. Distinguish between elements and compounds, and between compounds and mixtures.

6. What is the composition of the atmosphere? Give the outlines of a method for analysing it accurately. How is it proved to be a mixture and not a chemical compound?

7. I want to convert 132.4 grm. of lead nitrate into lead sulphate. How much potassium sulphate will effect this change, and how much lead sulphate shall I obtain? $(\mathrm{Pb}=207, \mathrm{~K}=39$.

In Physical Geography :-

r. How may the earth be proved to be a globe, and in what respects does it differ in form from a perfect sphere?

2. Show by examples how climate is affected by the position of a locality independently of the latitude?

3. Define the terms watershed, denudation. Give instances of denudation effected by rivers.

4. Explain the terms dip, strike, joints, and foults.

5. What is supposed to be the origin of coal, and on what facts is this supposition based ?

6. Name and describe fully the accompanying specimens :--

[Specimens: Granite, oolite, dolomite, selenite, and two bivalve fossils.]

It is to be remarked that, with the exception of the last question, there is no test of a practical kind at all. Is the knowledge of the composition of the air, of the reasons for believing that the earth is round, of the meaning of the terms watershed, dip, \&c, -is this the utmost that should be demanded of a boy of eighteen who has studied science instead of the older well-established subjects of classics and mathematics? 